\title{
THE MACHINERY SAFETY MANAGEMENT - SELECTED ISSUES
}

\author{
doi: $\quad 10.2478 /$ czoto-2019-0006
}

Date of submission of the article to the Editor: $18 / 11 / 2018$

Date of acceptance of the article by the Editor: 25/01/2019

\author{
Agata Kielesińska1-orcid id: 0000-0001-9974-7961 \\ Miroslav Pristavka ${ }^{2}$ \\ ${ }^{1}$ Czestochowa University of Technology, Poland, agata.kielesinska@wz.pcz.pk \\ ${ }^{2}$ Slovak University of Agriculture in Nitra, Slovakia
}

\begin{abstract}
In paper, the issues and the essence of labor protection in relation to EU and national legal standards in the field of machine safety have been presented. In the elaboration also, the requirements and selected issues of machine safety management in the sphere of their construction, production, distribution and operation have been defined. But above all, the general principles of hazard assessment and the technical measures applied to improve the safety of machines during their use have been presented.
\end{abstract}

Keywords: safety, machinery directive, essential requirements, minimum safety requirements, safety management

\section{INTRODUCTION}

The significant and the most common cause of accidents in the industry is related to the operation of machines and equipment (presses, machine tools, jacks, industrial robots) which pose a threat to the serving staff and the environment at work. Therefore, it is necessary to pay attention to the obligatory legal regulations and applied principles of risk assessment, as well as to emphasize the importance of methods to improve the machines safety. Work protection through: a system legal remedies, economic, organizational and technical measures to provide employees safety in the work process (Chinniah, 2015; Chybowski and Gawdzinska, 2016; Niciejewska and Klimecka-Tatar 2018; Pacana and Ulewicz 2017). It should be assumed that primary goal of labor protection is to protect the health and life of an employee. Thus, the basic objective of labor protection is to protect the health and life of employees in the work environment to ensure their ability to work, and thus provide them with a guarantee of economic and social safety (Malyovanyi et al. 2015; Skowron-Grabowska and Sobociński, 2018). However, in the light of international regulations: "... health is not only a lack of disease, but it is a state of physical, mental and social well-being" - in other words, in this approach, work protection is to ensure health as per this definition. The legal concept of "labor protection" is generally equated with the protective function of labor law, which covers all labor law norms and 
provisions regulating the duties and rules of responsibility. The principles of responsibility for their non-compliance and the norms of labor law have a protective character with regard to maintaining the permanence of the employment relationship, remuneration for work, determining the maximum working time and determining the number of non-working days (Mullen, 2017),

\section{METHODOLOGY OF RESEARCH}

In the study the desk research method, as method of searching for and analyzing information obtained from available sources has been used. The desk research tests presented in the paper include compilation, mutual verification and processing of legal documents and safety requirements, obtained from accredited companies, which performing tests and assessing the fulfillment of machine safety requirements. This issue has been regulated legally in the light of directives and harmonized national laws of the member state of the European Union. The problem of machine safety has been considered in respect to the orientation to the content of the basic EU directives.

\section{RESULTS AND DISCUSSION}

The general safety requirements for products, adopted by the Parliament and the European Council, in Directive 2001/95/EC are a priority in European Union law and oblige producers, importers and distributors to transfer to the market and make available only safe products on the EU market, i.e. those that under normal or foreseeable conditions of use, storage, installation, maintenance do not present any threat (or only a minimal threat) that corresponds to a high level of protection of safety and health.

Directive 2001/95/EC applicable to all products. Each of its provisions applies in the absence of special Community legislation regulating the safety of the products concerned. Where products are subject to specific safety requirements imposed by Community legislation, this Directive shall apply only in relation to the risks or categories of risks not covered by those requirements.

At the same time, EU legislation for specific product groups specifies safety regulations to identify hazards of the product. This also applies to machines, defined in the directive as: a set, fitted with or intended to be fitted with a drive mechanism other than directly employing human or animal muscle strength, consisting of conjugated parts or components, at least one of which moves, joined together for a specific application.

\subsection{Direct requirements for the machines safety}

The European Community has established a number of directives in the area of the machines safety and Directive 89/391/EEC introduces measures to improve the health safety at work and regulates the tasks of the parties involved in creating safe and healthy working conditions in the company. The implementation of these tasks and the application of specific rules for their implementation is to guarantee the stimulation of activities to ensure the safety of workers and its improvement, as defined in Article 1 of the directive: introduction of stimulus measures to improve safety and protect workers' health at work. This directive contains general principles: prevention of occupational risks, safety and health protection, elimination of accident and risk factors, information, consultation, participation of employees and their representatives (in accordance to national law) and their training, as well as general 
indications on the implementation of these principles. The requirements contained in this directive were introduced into Polish law in the Act of November 14, 2003 amending the Labor Code and amending some other acts (Journal of Laws No. 213, item 2081). Directive 89/391/EEC discussed above was called the Framework Directive. This name results from the fact that in Article 16.1. a delegation has been included that forms the basis for the issue of specific directives - including defining the essential requirements, including for machines and personal protective equipment. In terms of machine safety, there are two types of requirements, they are directed to:

- user - user should be guided primarily by current laws and regulations regarding safety and operation,

- manufacturer - the manufacturer undertakes to comply with the provisions of the Machinery Directive 2006/42/EC and other specific standards.

The technical and safety requirements have been set out in the annexes to the directives as well as in the technical standards. And the established conditions must be absolutely met. Only then, the product can be considered as safe for health and the environment, as well as it can be released for distribution to the market and for use. The safety directives also cover aspects related to other issues (Figure 1), e.g.:

- economic - related to the new global approach, design and production; define the essential requirements and conditions for placing machines on the market. The recipients of these directives are designers, constructors and producers. The basic economic directive is the machinery directive 2006/42/ EC,

- $\quad$ social - define the minimum health and safety requirements that employers should provide to employees. The social directives are: 89/391/EEC ("framework") and tool directive 2009/104/EC.

\begin{tabular}{|c|c|}
\hline SOCIAL ASPECT & ECONOMIC ASPECT \\
\hline $\begin{array}{c}\text { Economic Directives } \\
2006 / 42 / E C \\
\end{array}$ & $\begin{array}{c}\text { Social Directives } \\
\text { 89/391/EEC, 2009/104/EC }\end{array}$ \\
\hline ESSENTIAL REQUIREMENTS & MINIMUM REQUIREMENTS \\
\hline $\begin{array}{l}\text { new or modernized machines } \\
\text { and imported from outside the EU }\end{array}$ & $\begin{array}{c}\text { used machines before } 1.04 .2004 \\
\text { and work equipment }\end{array}$ \\
\hline $\begin{array}{ll}- & \text { designer } \\
- & \text { manufacturer } \\
- & \text { supplier } \\
- & \text { importer }\end{array}$ & - employer \\
\hline
\end{tabular}

Fig. 1. Basic directives on occupational health and safety

Directive 2006/42/EC - Machinery Directive - obligatorily defines the essential requirements for machines placed for the first time on the European Union market, concerning manufacturers, importers and other entities responsible for the product. In Poland, from December 2009, it is mandatory to apply the provisions of this directive (pursuant to the Regulation of the Minister of Economy of October 21, 2008 on essential requirements for machines). From 1 April 2004, that is from the date of Poland's accession to the European Union, the basic requirements based on EU legislation were in force. However, the legal act regulating the use of work equipment, including machinery, is Directive 2009/104/EC - Tooling Directive - specifying 
minimum requirements addressed to users of machines, in the mind of employers providing work equipment. This directive with reference to 89/655/EEC, merges and organizes existing legislation, so the regulation on minimum requirements regarding health and safety in the use of machines.

The process related to ensuring safety and limiting the risk level on the machine manufacturers side is based on the application in the design and production of the safety triad (figure 2) (Mössner, 2012).

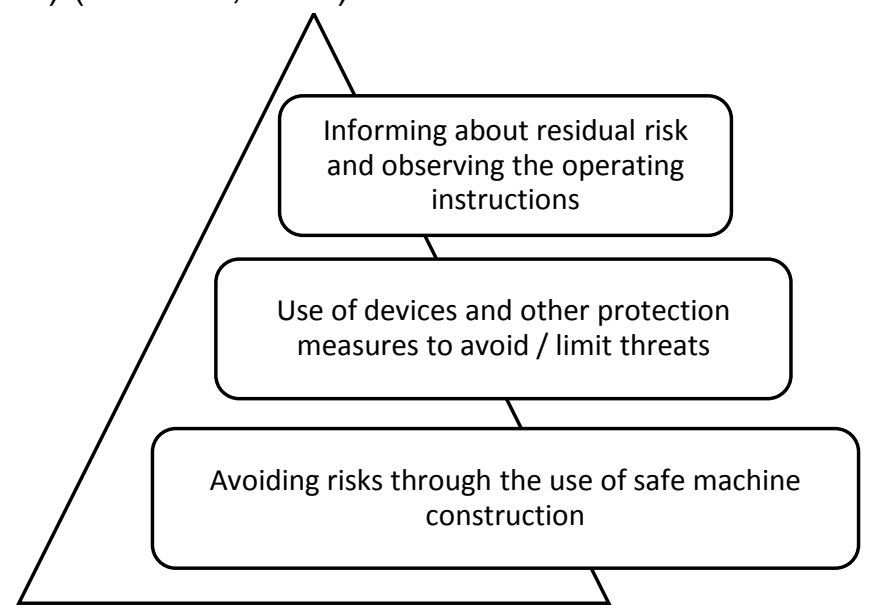

Fig. 2. Basic principles in the safety triad

The basis of the triad is the construction and production of safe machines, in which the risks associated with all hazards have been eliminated or reduced to a minimum. This applies to hazards at the level of: mechanical, electrical, thermal, noise hazard or the properties of processed materials. If there is a risk that cannot be eliminated at this level, the manufacturer applies additional protective measures such as covers and protective devices (Etherton, 2008; Mössner, 2012). The above activities never reduce the risk to zero, there is always a residual risk, therefore manufacturers is obliged to inform and warn in the operating instructions (through appropriate markings and pictograms).

\subsection{Technical safety measures}

Technical safety measures, are used to reduce or eliminate the hazard occurring during the operation of machines and, above all, the every moving parts, as well as the parts of drive system. The Machinery Directive (point 1.3.8) specifies that protective devices - depending on the type of risk (Baud et al., 2013):

- Shields and fences, separation (fencing) of the danger zone from persons in proximity, which is the most effective way to reduce the risk. Shields must have appropriate properties and a durable construction, do not create an additional hazard, can only cause minimal obstructions in the observation of the production process, and in the case of e.g. service treatment have to ensure simple disassembly with the use of tools. A special type of enclosure is a security fence (fencing) that allows adequate protection of a single machine or production line, taking into account the available space and safe distances from the danger zone.

- Protective devices (e.g. safety switches) that reduce the risk - constitute a monitoring device (opening monitoring sensors). It also includes locking devices, electromagnetic safety locks, all devices that block access to the 
danger zone Devices that also prevents the machine run while a person is in the danger zone and ensures safety and continuity of the technological process.

- Photoelectric safety devices, used as curtains and safety light barriers, which belong to the group of electro-sensitive (non-contact) protective devices. They complement the fencing system or function independently, and their task is to detect the presence of people in danger zones.

- Other components of safety systems - pressure-sensitive devices (activated by pressure on the working surface of the element), e.g. mats, bumpers, safety edges (strips).

\subsection{Operation of machines}

Operation of machines with ensuring the safety of service should be performed in accordance with the manufacturer's instructions and with care in maintaining the proper technical condition of the machine, and in particular compliance with the requirements of technical safety measures (Aneziris et al., 2013). It is also important to use organizational and systemic measures, such as: preparation of workplace instructions, periodic training of machine users, motivating for the use of safe work methods, and requiring the use of personal protective equipment by employees. The employer is the person responsible for applying measures to minimize the risks associated with the machinery operation, the employer is obligated to carry out and supervise the existing safety status (2009/104 / EC, Article 3). During operation of the machine, especially during maintenance and repair work - the employee is exposed to the potential risks associated with the energy sources used in the machine. European workplace protection standards require, that the machines and other work equipment to be cut off from the energy supply and secured in such a way that their unintentional connection is not possible. The solution used for this requirement is, inter alia, the implementation of the LOTO program, which is not mandatory. The security of LOTO requires the preparation of a machines list, development of the LOTO procedure, marking the machine and personnel training to recognizing the occurrence of danger in the scope of energy supply. In the LOTO program, padlocks, valve locks, cables etc. are used as a blockades.

\subsection{Recommendations for the machine designer/constructor}

Directive 2006/42 / EC defining the essential requirements for machines placed for the first time on the European Union market. The application of this directive is obligatory. The relatively broad scope of safety requirements, as well as the legal liability of producers / importers for the product being introduced into the EU market, often means that voluntary use of technical support and advice of notified certification unit is justified. For the machinery categories listed in Annex IV of the Directive, the assessment carried out by the certification unit is obligatory. One of these notified unit offers the use of a five-step methodology to ensure that machinery complies with the essential requirements. This methodology is based on the applicable national legal acts and accepted standards and is consistent with them. Its main advantage is a comprehensive approach to all the phases of the cycle ensuring machine compliance with the applicable safety requirements. The described methodology is distinguished in five stages are: (1) risk assessment and analysis, (2) concept of safety, (3) safety design, (4) implementation and (5) validation (Poh et al., 2018). 
The analysis and risk assessment is the most important element of the entire process of ensuring machine safety (Hietikko et al., 2011; Etherton, 2008). The risk analysis is carried out by inspecting the machine, focusing on:

- detection of existing threats and calculation of the HRN index for them,

- checking compliance with the directives, current standards and regulations,

- analysis of electrical documentation, safety instructions.

After the risk analysis, it is possible to develop a safety concept, and the prepared concepts are recommendations on which solutions should be applied. The preparation of a safety design refers to the creation of specific solutions for a given machine in relation to the directive requirements and standards, including in particular requirements for control systems and safety circuits according to PN-EN ISO 138491. However, the most important elements, are the implementation and evaluation, which include the changes execution according to the developed project. Especially, the complementary changes in the construction documentation, instructions, and also commercial documentation (Porras-Vazquez et al., 2018).

The presented 5-step methodology for ensuring machines compliance with safety requirements allows a systematic analysis of potential hazards, estimating the risk of a dangerous event, developing a safety concept that minimizes the risk to an acceptable level, designing the proposed solutions, implementing them and validating correctness and efficiency (Hietikko et al., 2011). As a result, it is the basis for proceedings regarding the CE declaration of conformity. The declaration of conformity is the manufacturer's confirmation of full responsibility for the product. The manufacturer declares that the product complies with the essential requirements. This declaration must be attached to the machine before it is placed on the market. The basis for issuing the declaration of conformity for the machine and its CE marking is positive test results confirming the improvement of machine safety and compliance with the relevant essential requirements and standards.

\subsection{Research and declaration of conformity}

Machine testing may include both measurements, calculations, analyzes and other similar activities that should be documented. Documents from research (reports), should clearly define the subject and scope of research, applied methods and equipment, and present the results, taking into account the uncertainty of measurement. These documents should have unambiguously defined features, e.g. numbers, date, contain names, surnames and signatures of contractors, as well as the names, surnames and signatures of approving persons. These documents, together with other certificates (e.g. materials, declarations of conformity for used elements) constitute data sources for collective assessment of the machine.

\subsection{Recommendations for the employer / machine user}

Due to the fact that the machinery directive 2006/42/EC does not cover "old machines" (already present in the territory of the European Union Member States) then the free market for used machines is possible when:

a) the machine is at the same level of safety as directly upon manufacturing (check the requirements of Directive 2009/104/ EC - minimum health and safety requirements,

b) the machine has not been modernized, has the original safety features, 
c) the machine meets the requirements of Directive 2001/95/ EC, general safety products.

The machine may be made available in the course of trade on the EU market and be used without CE marking and EC declaration of conformity. If, however, the safety of the "old machine" has been changed, then such a machine is considered as a "new" the person responsible for this machine becomes the producer and bears all responsibility and all the manufacturer's obligations.

\section{CONCLUSION}

The regulations of the Minister of Economy on the essential requirements for machines implement the Machinery Directive 2006/42/ EC concerning on the new machines and every machine first time introduced into the EU market, as well as the used machines (old), which are modernized and the original safety features have been changed. These provisions specify in detail the duties and responsibilities of the manufacturer, authorized representative, importer of the machines. They indicate unambiguously that only the machines meet the highest possible level of safety (confirmed by the positive results of the risk assessment tests and in compliance with obligatory regulations) can be authorized with the EC (declaration of conformity) and CE marking.

The obligation of the manufacturer (authorized representative, as well as the importer) is to provide on EU market only the machine that complies with the Directive 2006/42/EC and equipped with instructions for use, a declaration of conformity, full labeling (including $\mathrm{CE}$ ), as well as the basic accessories that will allow to use them without causing threats.

However, for machines already located in the EU (old) area, the legal act regulating their use, as well as other work equipment, is Directive 2009/104/EC - the so-called "Tooling directive", specifying minimum health and safety requirements, addressed to machine users (in the mind of employers) providing work equipment to employees.

\section{REFERENCES}

Aneziris, O.N., Papazoglou, I.A., Konstandinidou, M., Baksteen, H., Mud, M., Damen, M., Bellamy, L.J., Oh, J., 2013. Quantification of occupational risk owing to contact with moving parts of machines. Safety Science 51(1), 382-396. DOI: 10.1016/j.ssci.2012.08.009

Baud, K.C., Hinze, J.W., Hallowell, M.R., et al., 2013. Proactive construction safety control: measuring, monitoring, and responding to safety leading indicators.J. Constr. Eng. Manag. 139(10). DOI:10.1061/(ASCE)C0.1943-7862.0000730

BS EN 953:1997+A1:2009. Safety of machinery. Guards. General requirements for the design and construction of fixed and movable guards

Chinniah, Y., 2015. Analysis and prevention of serious and fatal accidents related to moving parts of machinery. Safety Science 75,163-173. DOI: 10.1016/j.ssci.2015.02.004

Chybowski, L., Gawdzinska, K., 2016. On the present state-of-the-art of a component importance analysis for complex technical systems. World Conference on Information Systems and Technologies (WorldCIST), BRAZIL, MAR 22-24, 2016. Advances in Intelligent Systems and Computing, 445, 691-700. DOI: 10.1007/9783-319-31307-8_70 
Directive 2001/95/EC of the European Parliament and of the Council of 3 December 2001 on general product safety (Text with EEA relevance)

Directive 2006/42/EC of the European Parliament and of the Council of 17 May 2006 on machinery, and amending Directive 95/16/EC (recast) (Text with EEA relevance)

Directive 89/391/EEC of 12 June 1989 on the introduction of measures to encourage improvements in the safety and health of workers at work

Etherton, J., Main, B., Cloutier, D., Christensen, W., 2008. Reducing risk on machinery: A field evaluation pilot study of risk assessment. Risk Analysis, 28(3), 711-721. DOI: 10.1111/j.1539-6924.2008.01045.x

Hietikko, M., Malm, T., Alanen, J., 2011. Risk estimation studies in the context of a machine control function. Reliability Engineering \& System Safety, 96(7), 767-774. DOI: 10.1016/j.ress.2011.02.009

ISO 13849-1:2006(en) Safety of machinery -- Safety-related parts of control systems - Part 1: General principles for design

ISO 13849-2:2012(en) Safety of machinery — Safety-related parts of control systems - Part 2: Validation

Malyovanyi, M., Barabash, L., Bondarenko, N., 2015. Socio-economic determinants' impact on financial support for social safety in Ukraine. Economic Annals-XXI, 34(2), 41-45

Mössner, T., 2012. GESIMA - Designing safe machines: BAUA (Federal Institute for Occupational Safety and Health) software for the risk assessment in machine construction. Technische Sicherheit, 2(1-2), 14-18.

Mullen, J., Kelloway, E.K., Teed, M., 2017. Employer safety obligations, transformational leadership and their interactive effects on employee safety performance. Safety Science, 91, 405-412. DOI: 10.1016/j.ssci.2016.09.007

Niciejewska, M., Klimecka-Tatar, D., 2018. Health problems among employees in small enterprises as a result of improper OHS management. 12th International Conference Quality Production Improvement, QPI 2018; Zaborze near Myszkow; Poland; 18 June 2018 through 20 June 2018; Code 139366 DOI: https://doi.org/10.1051/matecconf/201818301012

Pacana, A., Ulewicz, R., 2017. Research of determinants motiving to implement the environmental management system. Polish Journal of Management Studies, 16 (1), 165-174. DOI: 10.17512/pjms.2017.16.1.14

Poh, Clive Q. X., Ubeynarayana, Chalani Udhyami; Goh, Yang Miang, 2018. Safety leading indicators for construction sites: A machine learning approach. Automation in Construction 93, 375-386. DOI: 10.1016/j.autcon.2018.03.022

Porras-Vazquez, A., Romero-Perez, J-A., 2018. A new methodology for facilitating the design of safety-related parts of control systems in machines according to ISO 13849:2006 standard. Reliability Engineering \& System Safety, 174, 60-70. DOI: 10.1016/j.ress.2018.02.018

Skowron-Grabowska, B., Sobociński, M.D. 2018. Behaviour based safety (BBS) advantages and criticism. Production Engineering Archives 20, 12-15 DOI: 10.30657/pea.2018.20.03 